\title{
SEISMIC ANALYSIS OF ELEVATED COMPOSITE CONICAL TANKS
}

\author{
A. A. El Damatty ${ }^{1 *}$, A. M. El Ansary ${ }^{1}$, M. Jolie ${ }^{2}$ \\ ${ }^{1}$ Department of Civil and Environmental Engineering, The University of Western Ontario, \\ London, Ontario, Canada, N6A 5B9. (damatty@uwo.ca) \\ ${ }^{2}$ WorleyParsons, Calgary, Alberta, Canada.
}

\begin{abstract}
Truncated Conical vessels are commonly used as liquid containers in elevated tanks. Despite the widespread of this type of structures worldwide, no direct code provisions are currently available covering their seismic analysis and design. During a seismic excitation, two components of hydrodynamic pressure develop inside a liquid-filled tank. Those are the impulsive component, which synchronizes with the vibration of the walls of the tank and the convective component associated with the free surface sloshing motion. The current study describes the seismic behaviour of an elevated conical tank having a composite steel/concrete construction. The study is conducted numerically using a coupled finite/boundary element model developed in-house. The walls of the tank are modeled using a degenerated consistent shell element. The impulsive component of the hydrodynamic pressure is formulated taking into account the fluid-structure interaction that occurs between the fluid pressure and the shell vibration. The numerical model also predicts the sloshing motion associated with a seismic excitation. Due to the inclination of the walls, the vertical component of seismic ground motion produces meridional axial stresses in a conical tank. As such, both the horizontal and vertical components of the seismic motion are considered in the study. Time history seismic analyses are conducted under a number of pre-recorded seismic excitations. The bending and membrane stresses obtained from the analyses are evaluated in various location of the structure and are compared to the values associated with hydrostatic pressure in order to assess the importance of seismic stresses in this type of structures. The maximum values for the free surface sloshing motion are also obtained from the seismic analyses. Finally, comparisons are made between the seismic forces calculated using the equivalent cylinder approach adopted in some of the design codes.
\end{abstract}

Keywords: Seismic response, Conical tanks, Finite-Boundary element, Fluid-structure interaction.

\section{INTRODUCTION}

Storage tanks exist in various locations around the globe. A common use of such type of structures is for storage of water, oil and chemicals. The geometry of containment vessels with circular cross sections can be classified as: i) vessels consisting of pure cylindrical shells 
which are referred as "cylindrical tanks", ii) Vessels constructed from tapered cones as shown in Figure 1, which are denoted as "conical tanks", iii) Vessels consisting of truncated cones with superimposed top cylindrical caps which are referred as "combined conical tanks". During an earthquake event, the loss of function of such type of critical infrastructure systems, such as tanks that contain water or hazardous chemicals represents significant risk to life. Safety of water tanks during earthquakes is crucial for extinguishing fires that usually occur during such events.

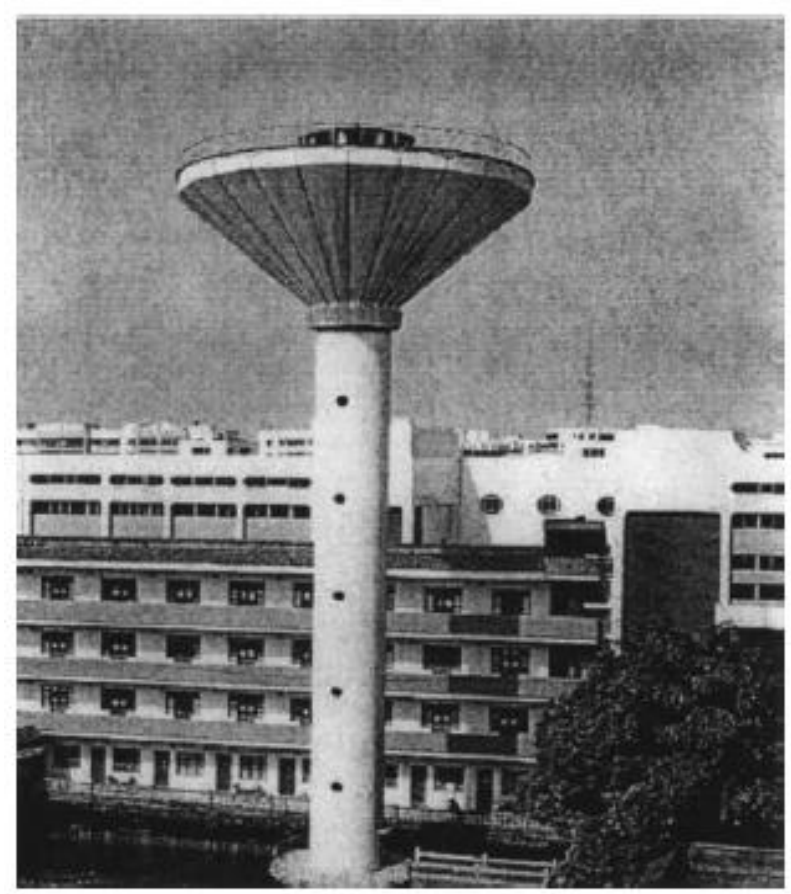

Figure 1. Elevated conical tank

In case of liquid-filled conical tanks, the inclination of the walls of the vessel complicates the state of stress. The stability of conical tanks under hydrostatic pressure has been investigated intensively by Vandepitte et al. [1] and El Damatty et al. [2, 3]. The outcome of these studies shows that hydrostatic pressure results in both meridional compressive stresses and hoop tensile stresses. Due to inclination of vessel walls, the seismic behaviour of a conical tank is expected to be different from the behaviour of a cylindrical tank. Research studies related to seismic behaviour of cylindrical vessels are quite intensive. An extensive literature survey summarizing these studies is reported by Cho et al. [4].

On the other hand, a limited number of studies are available in the literature for the seismic behaviour of conical and combined tanks. The first investigation related to the seismic behaviour of conical tanks was conducted by El Damatty et al. [5, 6]. A finite-boundary element approach that captures the fluid-structure interaction between fluid pressure and the vibration of the walls of the tank was used in these studies. This was followed by an experimental study that was conducted by Sweedan and El Damatty [7] to identify the dynamic response of empty and liquid-filled combined shells under lateral base excitation using shake table testing of scaled tank models. The experimental results of this study validated the as- 
sumption of de-coupling between the long-period fundamental sloshing oscillation and the structural response of the shell. The characteristics of the antisymmetric lateral modes of empty and liquid-filled combined vessels were identified experimentally and numerically in later studies conducted by El Damatty et al. [8, 9]. All previous research studies have revealed the following:

(1) Two types of hydrodynamic pressure develop in the tank vessel as a result of ground excitation: the impulsive component that synchronizes with the vibration of the tank and the sloshing component resulting from the free surface wave and having its own frequency of vibration.

(2) The flexibility of the walls of the tank significantly affects the impulsive component. This conclusion has been established after severe damage occurred to petrochemical tanks during the 1964 Alaska Earthquake [10].

(3) The free surface sloshing motion has a period of oscillation that is much longer than the fundamental period of the liquid-filled structure. As such, decoupling between the sloshing motion and the tank's vibration is usually assumed in the analysis.

The design of liquid-filled vessels is governed by the recommendations given in either the American Water Works Association [11], or the American Petroleum Institute [12], or the Euro-code 8 [13]. All these standards incorporate design procedures based on equivalent mechanical models developed for cylindrical shaped tanks. There are no current provisions specifically for the seismic design of liquid-filled conical tanks. In addition, to the best of the authors' knowledge, no guidelines currently exist for the seismic analysis and design of composite steel/concrete conical tanks. The current study is motivated by the lack of information in current design codes and in previous studies in the literature regarding the seismic behaviour of composite conical tanks.

In the first part of this study, an equivalent mechanical model that was developed by El Damatty and Sweedan [14] has been utilized to perform response spectrum analysis in order to determine the dynamic response of the composite conical tank. Maximum base shear, and overturning moment due to horizontal component and maximum vertical force due to vertical excitation have been evaluated. In the second part, a coupled finite/boundary element model developed in-house has been employed to simulate the liquid-shell continuum and the associated fluid-structure interaction phenomenon. This numerical model can predict both impulsive and sloshing components of the hydrodynamic pressure associated with a seismic excitation. The walls of the vessel are modeled using a degenerated consistent shell element, where an equivalent section has been calculated to simulate the composite steel/concrete section. Membrane and bending stresses obtained from the analyses are evaluated in various locations of the structure and are compared to the values associated with hydrostatic pressure in order to assess the importance of seismic stresses in this type of structures.

\section{TANK GEOMETRY AND EQUIVALENT PROPERTIES}

Figure 2 shows the geometry of the elevated conical tank examined in this study. In the shown figure, $R_{b}, \theta_{v}, h, h_{s}$ are the tank bottom radius, angle between tank generator and vertical direction, vessel height, and shaft height, respectively. As mentioned earlier, the tank 
wall is constructed of a composite steel/concrete section with a modulus of elasticity $E_{s}=$ $2 \times 10^{5} \mathrm{MPa}$ and $E_{c}=2.35 \times 10^{4} \mathrm{MPa}$ for steel and concrete, respectively. Curved steel plates having a constant thickness of $8 \mathrm{~mm}$ along the height are used in constructing tank walls. On the other hand, the thickness of the concrete section varies along the tank height, as shown in Figure 2 and Table 1. To simplify the analysis, an equivalent section approach has been assumed to simulate the composite steel/concrete section, which is varying along the height. This has been done at diffenernt tank heights and for both cases of cracked and uncracked sections. The equivalent section properties $\left(t_{e q}, E e q\right)$ at different heights are determined by calculating the effective axial stiffness $(E t)$ and bending stiffness $\left(E t^{3} / 12\right)$ of a unit width composite section as shown in Figure 2a. From these two equations, the properties of these equivalent sections $\left(t_{e q}, E e q\right)$ can be evaluated along the height, as shown in Table 1.

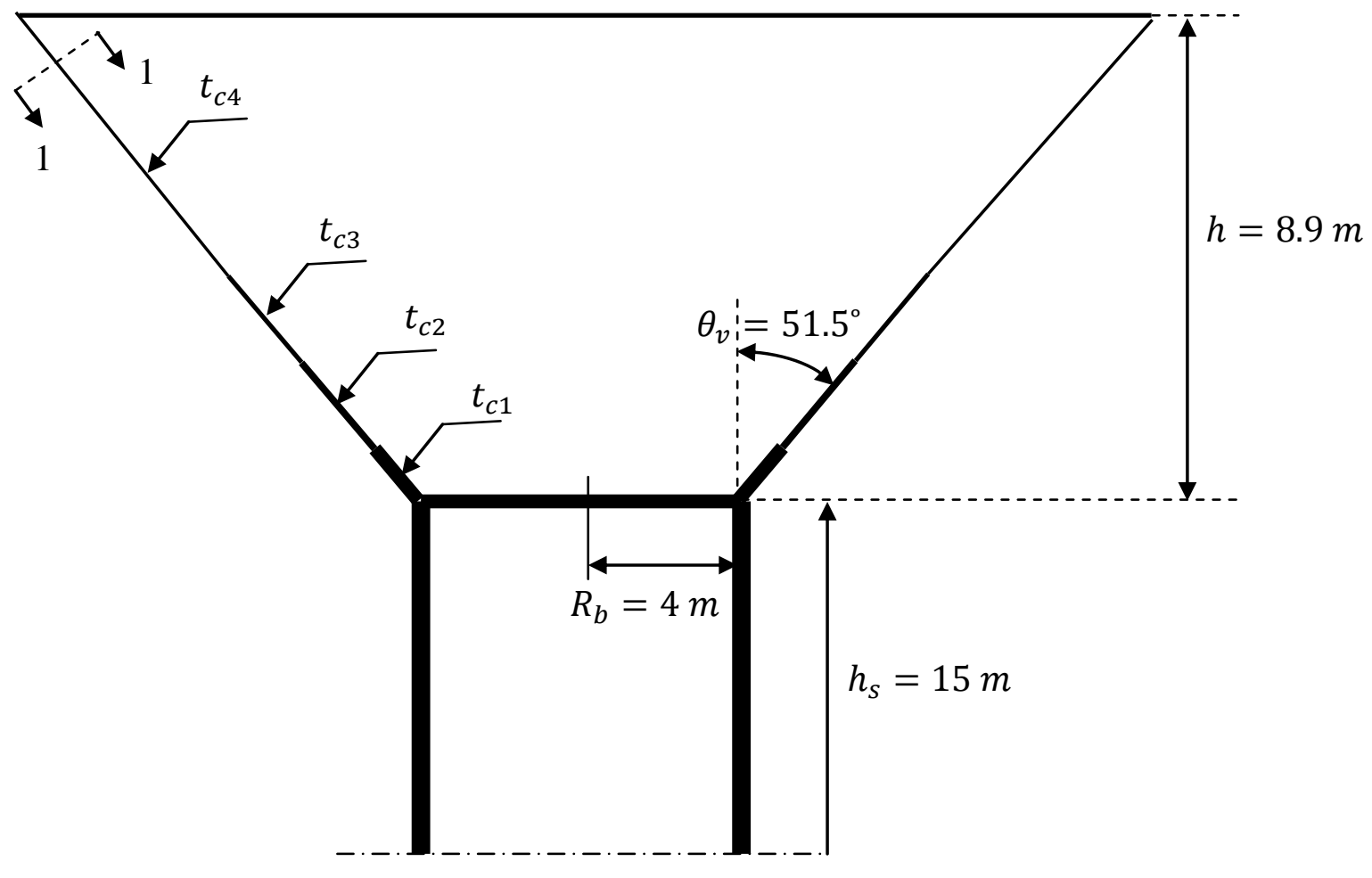

Figure 2. Dimensions and properties of the examined tank

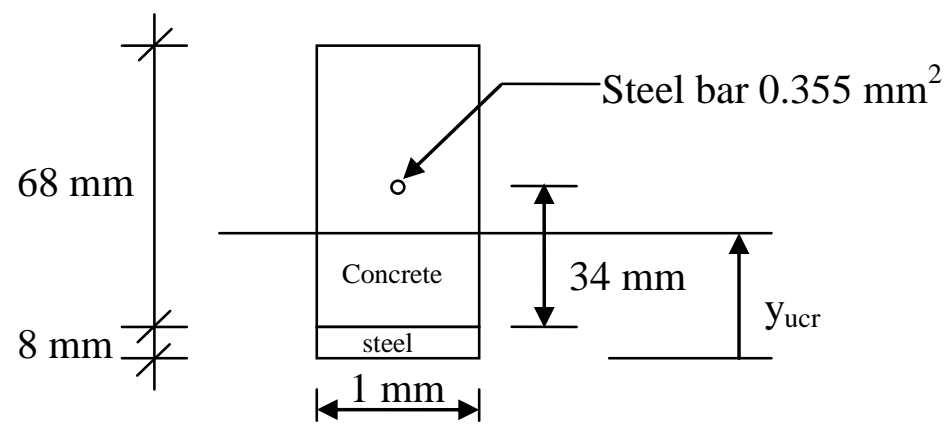

Figure 2a. Section (1-1) 
Table 1. Equivalent thickness and stiffness of the tank wall

\begin{tabular}{cccccc}
\hline \multirow{2}{*}{$\begin{array}{c}\text { Height } \\
\text { range }(\mathrm{m})\end{array}$} & $\begin{array}{c}\text { Thickness of } \\
\text { concrete section }\end{array}$ & \multicolumn{2}{c}{$\begin{array}{c}\text { Uncracked } \\
\text { section }\end{array}$} & \multicolumn{2}{c}{$\begin{array}{c}\text { Cracked } \\
\text { section }\end{array}$} \\
\cline { 3 - 6 } & $(m)$ & $t_{e q}(m)$ & Eeq $(M P a)$ & $t_{e q}(m)$ & $E e q(M P a)$ \\
\hline 0.0 to 1.0 & $t_{c 1}=0.112$ & 0.134 & $3.214 \times 10^{4}$ & 0.146 & $2.350 \times 10^{4}$ \\
1.0 to 2.2 & $t_{c 2}=0.095$ & 0.113 & $3.431 \times 10^{4}$ & 0.122 & $2.640 \times 10^{4}$ \\
2.2 to 3.4 & $t_{c 3}=0.082$ & 0.098 & $3.659 \times 10^{4}$ & 0.105 & $2.933 \times 10^{4}$ \\
3.4 to 8.9 & $t_{c 4}=0.068$ & 0.081 & $4.009 \times 10^{4}$ & 0.086 & $3.370 \times 10^{4}$ \\
\hline
\end{tabular}

\section{DESCRIPTION OF MECHANICAL MODELS FOR HORIZONTAL AND VERTI- CAL EXCITATION}

The current study utilizes the equivalent mechanical model developed by El Damatty and Sweedan [14] to perform response spectrum analysis in order to determine the dynamic response of the composite steel/concrete conical tank. Maximum base shear, overturning moments due to horizontal excitation and maximum vertical forces on tank walls and base due to vertical acceleration are evaluated in a range of seismic area.

\subsection{Mechanical model for horizontal excitation}

The mechanical model of an elevated conical tank supported on a shaft is shown in Figure 3. The mechanical model is a three-degree-of-freedom with the horizontal ground excitation applied at the base of the supporting shaft. The spring $K_{O}$ represents the stiffness of the shaft. The model is composed of rigid, flexible and sloshing components. Eight parameters are required to fully describe the equivalent model. These parameters are the natural frequencies of the first $\cos \theta$ impulsive mode $f_{I}$, the fundamental sloshing mode $f_{s}$, the masses $m_{o}$, $m_{f}$ and $m_{s}$, and the elevation of these masses $h_{o}, h_{f}$, and $h_{s}$. The rigid mass component $m_{o}$ represents the effective mass associated with the higher impulsive modes. The mass is attached rigidly to the tank at a height $h_{o}$. The flexible mass component $m_{f}$ represents the effective mass associated with the fundamental impulsive mode. This mass vibrates with the tank wall deformation relative to the base, connected by a spring with stiffness $k_{f}$ and located at a height $h_{f}$ above the tank base. The effective mass $m_{s}$ corresponds to the contribution of mass that acts in the long period sloshing mode. This mass is connected to the tank wall with stiffness $k_{s}$ and located at a height $h_{s}$ above the tank base. The equivalent heights above the tank base correspond to the location of the masses that replicates the overturning moment acting on the vessel.

The fundamental frequencies, mass and height parameters mentioned above are determined from charts developed in a previous investigation that was conducted by El Damatty and Sweedan [14]. Knowing the frequency and mass parameters, the stiffness values can be evaluated as $K_{f}=4 \pi^{2} f_{I}^{2} m_{f}$ and $K_{s}=4 \pi^{2} f_{s}^{2} m_{s}$. Using the above parameters, the equivalent mechanical model can be used to evaluate the response of liquid-filled composite conical tanks subjected to a horizontal excitation. The maximum base shear experienced from the 
rigid $\left(V_{o-\max }\right)$, flexible $\left(V_{f-\max }\right)$, and sloshing $\left(V_{s-\max }\right)$ mass components are determined using the response spectrum approach as:

$$
\begin{aligned}
& V_{o-\max }=m_{o}\left(S_{a}\right)_{o} \\
& V_{f-\max }=m_{f}\left(S_{a}\right)_{f} \\
& V_{s-\text { max }}=m_{s}\left(S_{a}\right)_{s}
\end{aligned}
$$

where $\left(S_{a}\right)_{o}$ is the spectral response acceleration of the rigid fluid mass $m_{o}$, while $\left(S_{a}\right)_{f}$ and $\left(S_{a}\right)_{s}$ are the spectral response accelerations of the flexible $m_{f}$ and sloshing $m_{s}$ masses, respectively. The maximum total base shear $V_{\max }$ can be determined by adding the base shear components using the Square Root of the Sum Squares (SRSS) combination rule as shown in equation (4).

$$
V_{\max }=\sqrt{V_{o-\max }^{2}+V_{f-\max }^{2}+V_{s-\max }^{2}}
$$

Similarly, using response spectrum analysis, the maximum overturning moment resulting from horizontal excitation of each mass component can be determined as:

$$
\begin{aligned}
& M_{o-\max }=m_{o} h_{o}\left(S_{a}\right)_{o} \\
& M_{f-\max }=m_{f} h_{f}\left(S_{a}\right)_{f} \\
& M_{s-\max }=m_{s} h_{f}\left(S_{a}\right)_{f}
\end{aligned}
$$

The maximum total overturning moment experienced from the response of all three mass components can be evaluated using the SRSS combination rule as:

$$
M_{\max }=\sqrt{M_{\mathrm{o}-\max }^{2}+M_{\mathrm{f}-\max }^{2}+M_{\mathrm{s}-\max }^{2}}
$$

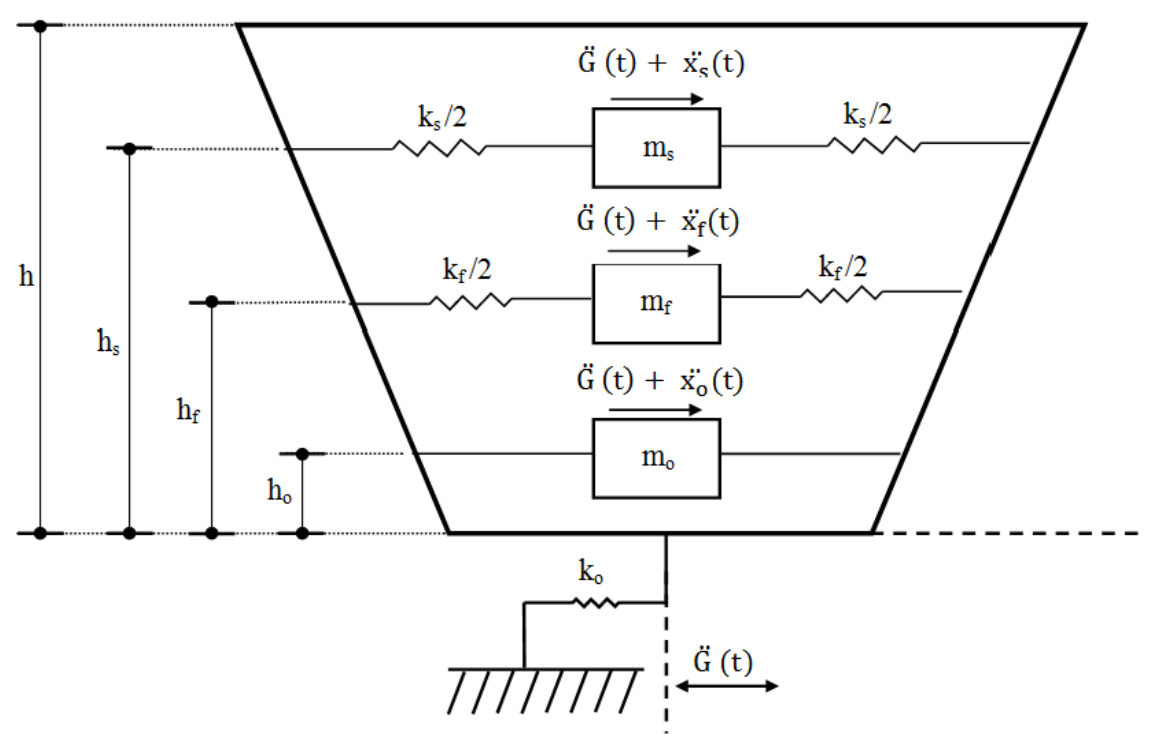

Figure 3. Equivalent mechanical model of an elevated tank for horizontal excitation 


\subsection{Mechanical model for vertical excitation}

Figure 4 shows a mechanical model of the tank for case of vertical acceleration. The model is two degree of freedom system comprising of the rigid mass $m_{o}$ and the flexible mass $m_{f}$. The rigid mass $m_{o}$ is attached to the base of the vessel and is assumed to vibrate with the applied ground motion. The flexible mass $m_{f}$ vibrates with the deformable tank walls at the axisymmetric impulsive frequency $f_{v}$. The mass is attached to the base of the tank with stiffness $k_{f}$. This equivalent model can be described by three parameters: the fundamental natural frequency of the axisymmetric mode $f_{v}$, and the masses $m_{o}$ and $m_{f}$. These parameters are obtained from charts developed by Sweedan and El Damatty [15] as a function of tank geometry. By knowing the natural frequency and the mass, the stiffness value can be evaluated as $k_{f}=4 \pi^{2} f_{v}^{2} m_{f}$. The equivalent mechanical model is capable of determining the total normal compressive forces acting on cross-section 1-1 and 2-2 shown in Figure 4. The force $N_{w}$ acting on cross section 1-1 represents the normal force induced in the walls of the tank, while $N_{b}$ represents the normal force induced on the tank support. The force acting on the walls of the tank $N_{w}$ is governed by the mass $m_{\text {cone }}$ of the fluid located in the conical volume. The effective masses to determine the normal compressive force acting on the walls are denoted as $m_{f-w}$ and $m_{o-w}$. The total normal compressive force acting on the base plate $N_{b}$ is dependent on the total fluid mass $m_{T}$ contained in the conical vessel. The effective masses in this case are denoted by $m_{f-b}$ and $m_{o-b}$. These effective masses are determined using charts developed by Sweedan and El Damatty [15]. In the current study, both flexible and rigid fluid masses are lumped together as $m_{r-w}$ and $m_{r-b}$ and assumed to act with the impulsive flexible response acceleration. Accordingly, the normal compressive force on the tank walls and the base plate can be evaluated using the response spectrum approach as:

$$
\begin{aligned}
N_{w} & =m_{r-w}\left(S_{a}\right)_{f v} \\
N_{b} & =m_{r-b}\left(S_{a}\right)_{f v}
\end{aligned}
$$

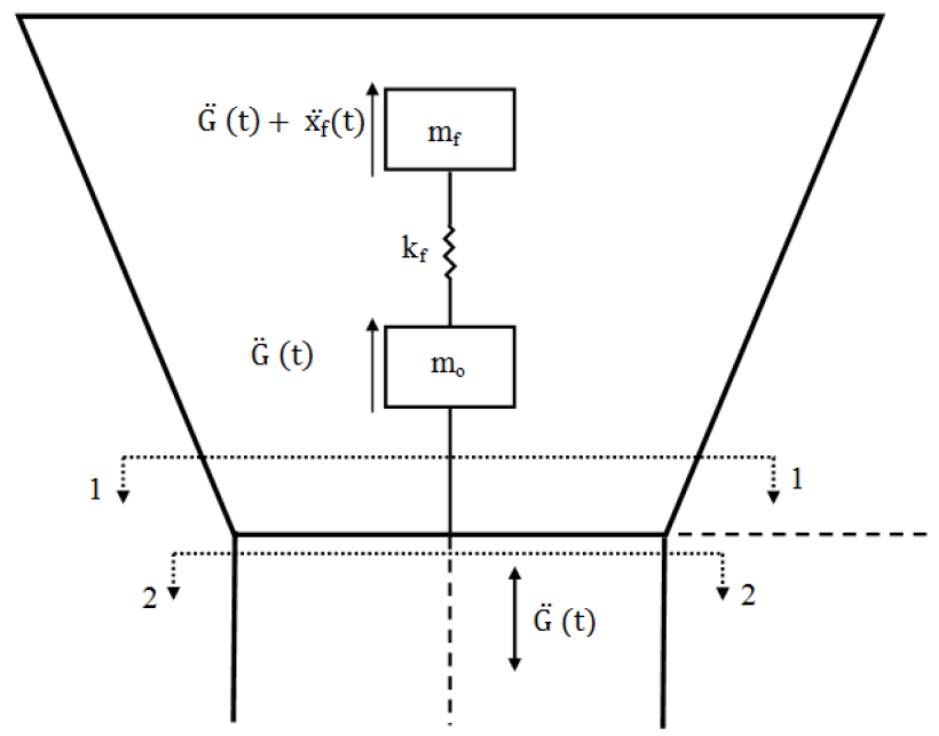

Figure 4. Equivalent mechanical model of an elevated tank for vertical excitation 


\section{MAXIMUM FORCES FROM MECHANICAL MODEL}

In this section, the mechanical models described previously have been utilized to perform response spectrum analysis in order to determine the dynamic response of the composite steel/concrete conical tank. The analysis is conducted based on a specific prerecorded seismic excitation. Both horizontal and vertical design spectrums are considered as will be shown in the next sub-sections.

\subsection{Horizontal excitation}

By using the equivalent model charts developed by El Damatty and Sweedan [14] for case of horizontal acceleration, periods, masses and equivalent heights are determined for the rigid impulsive, flexible impulsive and sloshing components. Table 2 summarizes the values of these parameters based on the specified tank dimension ratios $\left(h / R_{b}\right)$ and $\left(t_{e q} / R_{b}\right)$. It should be noted that the rigid period cannot be determined using equivalent model charts as it depends on the stiffness of the tank shaft. By evaluating the lateral stiffness and the mass of the shaft, the period of the shaft can be calculated, which will be the same period of the rigid impulsive component as shown in Table 2.

Table 2. Parameters required for horizontal excitation mechanical model

\begin{tabular}{cccc}
\hline Parameter & $\begin{array}{c}\text { Rigid impulsive } \\
\text { component }\end{array}$ & $\begin{array}{c}\text { Flexible impulsive } \\
\text { component }\end{array}$ & Sloshing component \\
\hline Period (Sec) & 0.054 & 0.372 & 7.05 \\
Effective mass $(\mathrm{Kg})$ & 106017 & 368822 & 2025161 \\
Equivalent height $(\mathrm{m})$ & 11.27 & 13.65 & 16.37 \\
\hline
\end{tabular}

5\% Horizontal Design Spectrum

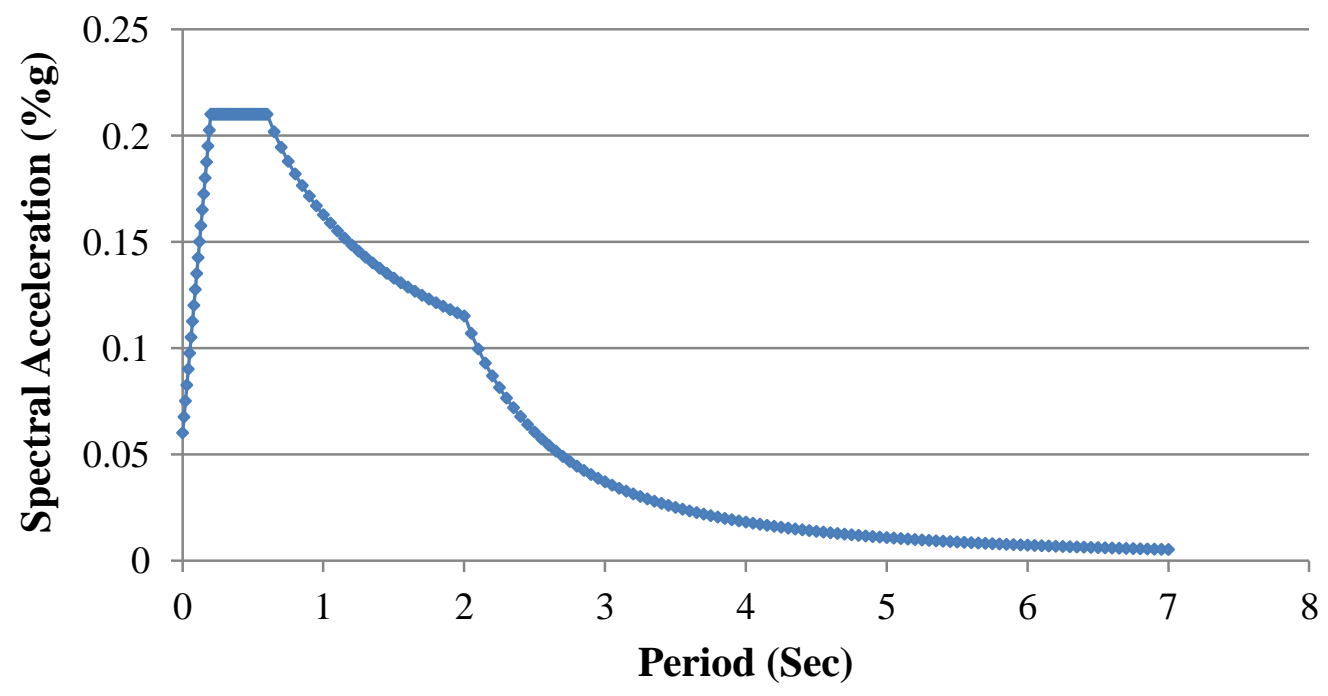

Figure 5. Horizontal acceleration spectrum for viscous damping of 5\%

Figure 5 shows a horizontal acceleration design spectrum for an equivalent viscous damping of $5 \%$. As shown in figure, the spectrum has a plateau from $\mathrm{T}=0.2 \sec$ to $\mathrm{T}=0.6$ $\mathrm{sec}$ and the displacement-sensitive region begins at $\mathrm{T}=2 \mathrm{sec}$. It is assumed that the plateau on 
the response spectrum extends to a period of $\mathrm{T}=0 \mathrm{sec}$. Based on the periods of different components shown in Table 2 and the horizontal design spectrum shown in Figure 5, the spectral acceleration of the rigid $\left(S_{a}\right)_{o}$, flexible $\left(S_{a}\right)_{f}$ and sloshing $\left(S_{a}\right)_{s}$ components are $0.1 \mathrm{~g}, 0.21 \mathrm{~g}, 0.007 \mathrm{~g}$, respectively. Accordingly, the maximum base shear $V_{\max }$ and maximum moment $M_{\max }$ can be evaluated using equations ( 1 to 4 ) and equations ( 5 to 8 ), respectively. In the current investigation, it is decided to lump both impulsive rigid and flexible fluid masses together $\left(m_{r}=m_{0}+m_{f}\right)$. As such, the base shear due to impulsive and sloshing components can be evaluated as shown in equations (11) and (12), respectively.

$$
\begin{gathered}
V_{\text {imp }}=m_{r} .\left(S_{a}\right)_{f} \\
V_{\text {slosh }}=m_{s} \cdot\left(S_{a}\right)_{s}
\end{gathered}
$$

By using the Square Root of the Sum Squares (SRSS) combination rule, a maximum base shear $V_{\text {max }}=988 \mathrm{kN}$ is determined due to the acceleration of the fluid masses. Following a similar approach for moments, a maximum moment $M_{\max }=13034 \mathrm{kN}$. $\mathrm{m}$ is determined.

\subsection{Vertical excitation}

In case of vertical excitation, the model acts in the same way except that only rigid and flexible modes are present. Also in this case, it is decided to lump the rigid and flexible fluid masses and act with the impulsive flexible response acceleration. The vertical flexible impulsive period and masses are determined using charts developed by Sweedan and El Damatty [15]. Based on these charts, the values of the vertical flexible impulsive period $T_{f-v}$, and masses $m_{r-w}$ and $m_{r-b}$ are $0.274 \mathrm{sec}, 1725049 \mathrm{~kg}$, and $2500000 \mathrm{~kg}$, respectively. Accordingly, a vertical spectral acceleration $\left(S_{a}\right)_{f v}$ can be determined from Figure 5. By applying equations (9) and (10), normal compressive forces $N_{w}=2399 k N$ acting on the tank walls and $N_{b}=3476 k N$ acting on the base are evaluated.

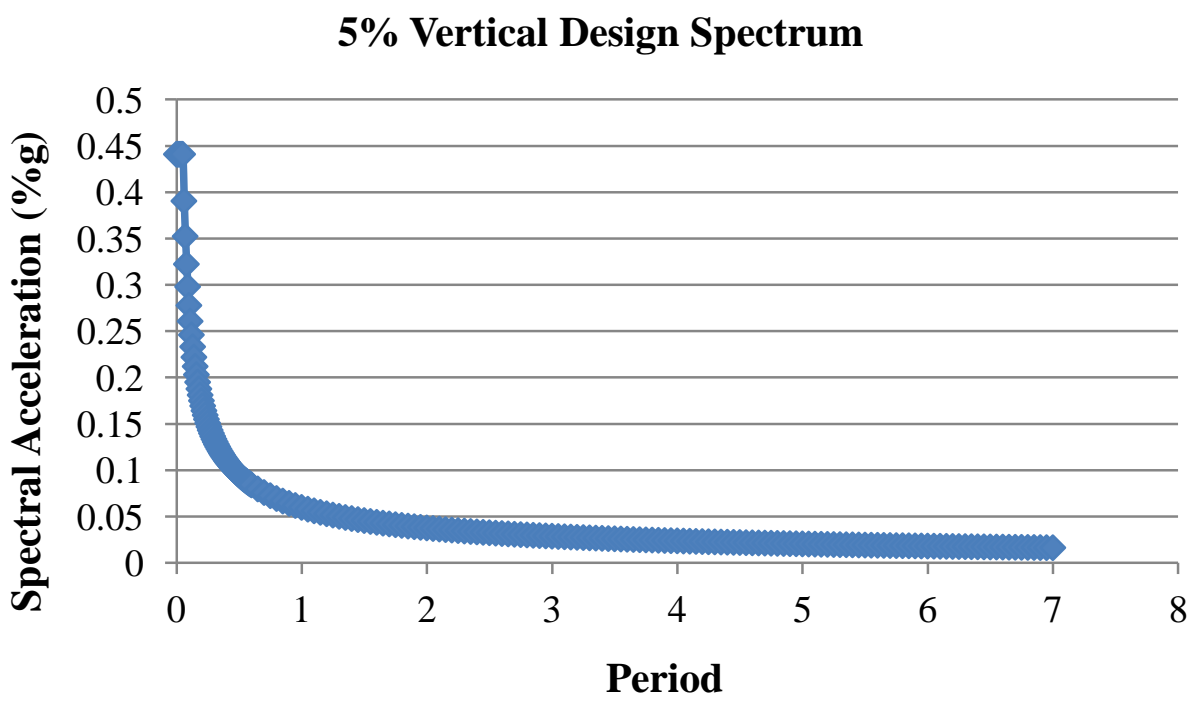

Figure 5. Vertical acceleration spectrum for viscous damping of 5\% 


\section{NUMERICAL MODEL}

This part of the study is conducted using a coupled finite-boundary element code built in-house. Only the walls of the vessel are modeled in this phase of analysis using a consistent degenerated triangular sub-parametric shell element as shown in Figure 6. The base of the vessel and the supporting tower are not included in the analysis. In addition, the solid mass of the vessel is excluded from the analysis. As a result of the symmetry in geometry, and excitation, only one-half of the tank is modeled using 512 shell elements. The analyzed tank is assumed to be free at its top rim and hinged boundary conditions are assumed at the tank base.

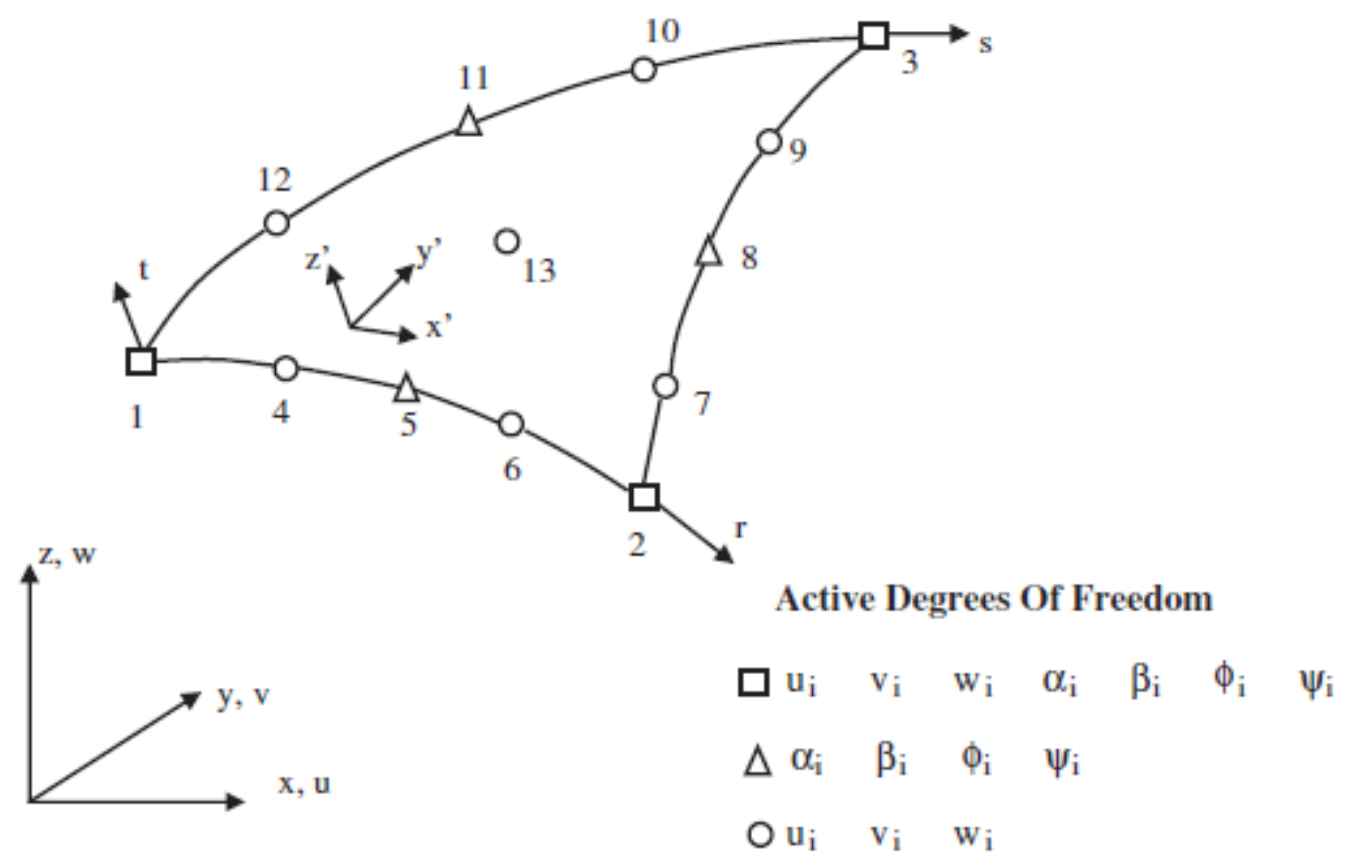

Figure 6. Consistent shell element degrees of freedom

The coupled finite/boundary element model can predict membrane and bending stresses induced in the tank's wall due to the effect of horizontal and vertical acceleration by applying the right distribution of hydrodynamic pressure. This can be done by the following procedure:

(1) The maximum shear force $V_{\max }$ developing at the base of the vessel can be evaluated using the proposed mechanical analog described in previous sections.

(2) Assuming that the maximum shear force $V_{\max }$ results entirely from the fundamental $\cos (\theta)$-impulsive mode, the following relation can be established:

$$
V_{\max }=c \int I_{1}\left(\alpha_{1} r\right) \cos \left(\alpha_{1} \mathrm{z}\right) \cos (\theta) \mathrm{dA}
$$

in which the integrand represents the distribution of the fundamental $\cos \theta$-impulsive mode, $\alpha_{1}$ depends on the height of the fluid, $I_{1}$ is the modified Bessel's function of the first kind, and $c$ is a coefficient (with pressure units) that is multiplied by the first 
pressure mode to give the pressure function acting on the tank walls associated with the maximum value of base shear $V_{\text {max }}$ obtained from previous step.

(3) Performing the above integration and the substituting in equation (13) to match the value of $\mathrm{V}_{\mathrm{max}}$, a value of $c$ can be obtained associated with the required hydrodynamic pressure distribution.

The same steps can be applied again for case of vertical excitation where the hydrodynamic pressure distribution in such case can be determined by matching $\mathrm{N}_{\max }$ obtained from mechanical analog with equation (14) to evaluate the pressure coefficient $c$.

$$
N_{\text {max }}=c \int I_{0}\left(\alpha_{1} r\right) \cos \left(\alpha_{1} \mathrm{z}\right) \mathrm{dA}
$$

\section{RESULTS OF NUMERICAL MODEL}

A three-dimensional finite element analysis has been conducted for three different cases. First case is conducted under the effect of hydrostatic pressure, while second and third cases are conducted under hydrodynamic pressure due to horizontal and vertical acceleration, respectively. The analysis started by assuming that the section is uncracked. In order to assess the effect of cracked section on the results, the same set of analyses is repeated based on properties of cracked section. Membrane and total stresses at the center of each element are recorded and the maximum meridional stresses are obtained. By comparing both uncracked and cracked section results, it is concluded that there is no major change in stresses can be noticed. As such, it was decided to report results of only one set as shown in Table 3. The results shown in Table 3 provide maximum membrane and maximum total meridional stresses induced in the tank walls due to the three cases mentioned before. In addition, in order to assess the importance of seismic stresses in such type of structures, stresses obtained from hydrodynamic pressure are compared to the values associated with hydrostatic pressure. It can be noticed from Table 3 and Figure 7 that horizontal acceleration leads to an increase of about $38.3 \%$ and $54.9 \%$ of the static stresses in membrane and total stresses, respectively. On the other hand, an increase in stresses of about $16.4 \%$ and $17.6 \%$ is noticed due to vertical excitation. This significant increase in stresses emphasizes the importance of considering the impact of the horizontal and vertical excitation on the design of liquid-storage tanks. It should be noted that the obtained numerical values are applicable for the particular vessel dimensions and earthquake record considered in the current study. As such, the increase in the stresses may fluctuate depending on the geometry of the tank and the intensity and frequency content of the applied ground excitation.

Table 3. Maximum membrane and total meridional stresses

\begin{tabular}{cccccc}
\hline $\begin{array}{c}\text { Max. } \\
\text { Stress }\end{array}$ & $\begin{array}{c}\text { Hydrostatic } \\
\text { pressure } \\
\text { stresses } \\
(\mathrm{MPa})\end{array}$ & $\begin{array}{c}\text { Hydrodynamic } \\
\text { pressure stresses } \\
(\mathrm{MPa}) \text { (horizon- } \\
\text { tal excitation) }\end{array}$ & $\begin{array}{c}\text { Hydrodynamic } \\
\text { pressure stresses } \\
(\mathrm{MPa}) \text { (vertical } \\
\text { excitation) }\end{array}$ & $\begin{array}{c}\text { Stress in- } \\
\text { crease due to } \\
\text { horizontal } \\
\text { excitation }(\%)\end{array}$ & $\begin{array}{c}\text { Stress increase } \\
\text { due to vertical } \\
\text { acceleration } \\
(\%)\end{array}$ \\
\hline $\begin{array}{c}\text { Membrane } \\
\text { stresses } \\
\text { Total } \\
\text { stresses }\end{array}$ & -6.65 & -2.55 & -1.09 & $38.3 \%$ & $16.4 \%$ \\
\hline
\end{tabular}




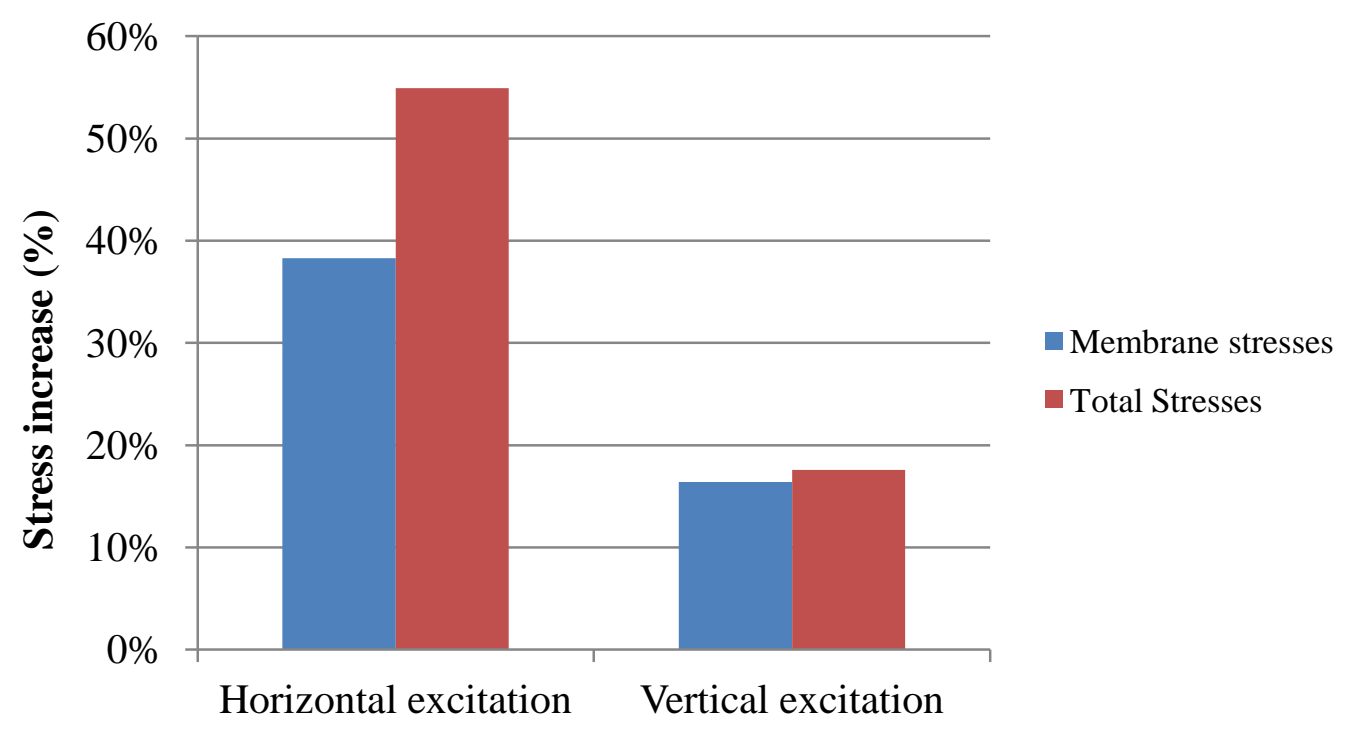

Figure 7. Stress increase due to seismic excitation

\section{SUMMARY AND CONCLUSIONS}

The dynamic response of an elevated conical tank having a composite steel/concrete construction is investigated. An equivalent mechanical model is proposed to predict the seismically induced forces due to both horizontal and vertical excitation. A coupled finite/boundary element model developed in-house has been utilized to predict membrane and bending stresses at various locations of the structure. Maximum membrane and total stresses has been recorded and compared to stresses associated with hydrostatic pressure. The following main conclusions can be drawn from the current study:

1) The results of the analyses show that there is no major change in stress values between cracked and uncracked sections.

2) For the particular studied tank and earthquake record used in the current study, it is noticed that horizontal excitation leads to a significant increase in membrane and total stresses of about $38.3 \%$ and $54.9 \%$, respectively. These values are based on comparing hydrodynamic pressure stresses to the values associated with hydrostatic pressure.

3) An increase in membrane and total stresses of about $16.4 \%$ and $17.6 \%$ is noticed due to vertical acceleration.

\section{REFERENCES}

[1] Vandepitte D, Rathe J, Verhegghe B, Paridaens R, Verschaeve C. "Experimental investigation of hydrostatically loaded conical shells and practical evaluation of the buckling load". In: Proceedings of state-of-the-art colloquium. Germany: Universitat Stuttgart; 1982. p. 375-99. 
[2] El Damatty AA, Korol RM, Mirza FA. "Stability of imperfect conical tanks under hydrostatic loading”. J. Struct. Eng. ASCE 1997; 123(6):703-12.

[3] El Damatty AA, El-Attar M, Korol RM. "Simple design procedure for liquid-filled steel conical tanks". J. Struct. Eng. ASCE 1999; 125(8): 879-90.

[4] Chao JR, Song JM, Lee JK. "Finite element techniques for the free-vibration and seismic analysis of liquid-storage tanks". Finite Elements in Analysis and Design 2001; 43:1398417.

[5] El Damatty AA, Korol RM, Mirza FA, 1997, "Stability of elevated liquid-filled conical tanks under seismic loading”. Part I-Theory, Earthquake Engineering and Structural Dynamics, Volume 26, pages: 1191-1208.

[6] El Damatty AA, Korol RM, Mirza FA, 1997, "Stability of elevated liquid-filled conical tanks under seismic loading". Part II-Applications, Earthquake Engineering and Structural Dynamics, Volume 26, pages: 1209-1229.

[7] Sweedan AMI, El Damatty AA, "Shake table testing of conical tank models". In: Proceeding of the third structural specialty conference, London, Ontario, Canada: CSCE 2000, p. 177-84.

[8] El Damatty AA, Saafan MS, Sweedan AMI, "Dynamic characteristics of combined conical-cylindrical shells". Journal of Thin-walled Structures 2005; 43: 1380-97.

[9] El Damatty AA, Saafan MS, Sweedan AMI. "Experimental study conducted on a liquidfilled combined conical tank model". Journal of Thin-walled Structures 2005; 43: 1398417.

[10] Veletsos AS, "Seismic effects in flexible liquid storage tanks". In: Proceeding of the fifth world conference on earthquake engineering. Rome, Italy; 1974. p. 630-9.

[11] American Water Works Association (AWWA), 2005. "Welded Steel Tanks for Water Storage", AWWA D-100, Denver, CO.

[12] American Petroleum Institute (API), 2005. "Welded Storage Tanks for Oil Storage", API 650, American Petroleum Institute Standard, Washington D.C.

[13] European Committee for Standardization (ECS), 1998. Design Provisions for Earthquake Resistance of Structures, Part I - General Rules and Part 4 - Silos, Tanks, and Pipelines, Eurocode 8, Brussels, Belgium.

[14] El Damatty AA, and Sweedan AMI, 2006, "Equivalent mechanical analog for dynamic analysis of pure conical tanks", Journal of Thin-Walled Structures, Volume 44, pages: 429-440. 
[15] Sweedan AMI, and El Damatty AA, 2005. Equivalent Models of Pure Conical Tanks under Vertical Ground Excitation, Journal of Structural Engineering, Volume 131, Issue 5, pages: $725-733$. 